\title{
Diversidade genética em quiabeiro baseada em marcadores RAPD
}

Gilmar E. Martinello; Nilton R. Leal; Antônio T. do Amaral Júnior; Messias G. Pereira; Rogério F. Daher UENF, CCTA, LMGV, Av. Alberto Lamego, 2000 - Horto, 28.0150620 Campos dos Goytacazes-RJ; E-mail: gilmartinello@ hotmail.com

\section{RESUMO}

Avaliou-se a utilização de marcadores RAPD para estimar a diversidade em 42 acessos do gênero Abelmoschus e um de Hibiscus. As estimativas das distâncias genéticas foram feitas com base no complemento aritmético do Índice de Jaccard. Foram utilizadas as técnicas de análise multivariada, através de agrupamento hierárquico do vizinho mais próximo e método de Tocher, para estudar os arranjos dos grupos de genótipos, bem como analisar os métodos de agrupamentos empregados. Trinta e um iniciadores foram utilizados para amplificar fragmentos de DNA pela reação de polimerização em cadeia (PCR) e foram gerados 103 fragmentos RAPD. O agrupamento hierárquico dos 43 genótipos com base no método do vizinho mais próximo separou os acessos, de modo geral, conforme as espécies botânicas, formando 6 grupos distintos. Isto foi confirmado pela projeção das distâncias genéticas no plano bidimensional, onde o primeiro e maior dos grupos reuniu os acessos de A. esculentus e A. caillei. Por outro lado, o método de Tocher reuniu $90 \%$ do germoplasma no grupo I incluindo, neste, os acessos de A. moschatus e $A$. manihot, além das outras duas espécies anteriores. O método de otimização de Tocher permitiu a formação de apenas 4 grupos de genótipos, mostrando-se coerente apenas em parte à análise de agrupamento hierárquico. Porém, o reagrupamento dos acessos do grupo I de Tocher pelo método hierárquico, revelou a existência de maior heterogeneidade genética no germoplasma estudado.

Palavras-chave: Abelmoschus esculentus, análise multivariada, distâncias genéticas, recursos genéticos.

\begin{abstract}
Genetic diversity in okra using RAPD markers

RAPD markers were utilized to estimate the diversity among 42 Abelmoschus and 1 Hibiscus accessions. The genetic distances were based on the arithmetic complement of the Jaccard index. For this purpose we used the multivariate analysis technique by hierarchycal single linkage and the Tocher methods to obtain the genotypes agglomeration as well as to analyze the methods employed. Thirtyone random decamer primers were used do amplify DNA by the polymerase chain reaction (PCR) and 103 RAPD fragments were generated. The hierarchycal method of single linkage has separated 43 genotypes, in a general way, according to the botanical species, forming six different groups. The genetic distances projection on the bidimentional level confirmed that the first and largest group has united A.esculentus and A. caillei accessions. On the other hand, the Tocher method grouped $90 \%$ of the germoplasm at group I, including A. moschatus and A. manihot accessions, besides the other two previous species. The Tocher optimization method allowed the formation of just 4 genotype groups. There was only partial coherence to the hierarchycal grouping analysis. The Tocher group I accessions regrouping by the hierarchycal method revealed the existence of a most important genetic heterogenity on the studied germplasm.
\end{abstract}

Keywords: Abelmoscus esculentus, multivariate analysis, genetics distances, genetics resources.

\section{(Recebido para publicação em 7 de fevereiro de 2002 e aceito em 28 de outubro de 2002)}

$\mathrm{O}$ quiabeiro [Abelmoschus esculentus (L.) Moench] é cultivado extensivamente em todas as regiões tropicais e subtropicais da Ásia, África e Américas. No Brasil, pode ser cultivado o ano todo, com obtenção de altas produções. É nítida e bastante expressiva a importância nutricional, econômica e social da cultura, embora a sua pesquisa básica seja ainda incipiente, principalmente no que se refere à organização genética do complexo poliespecífico. Neste sentido, torna-se necessário o aprofundamento do conhecimento em nível fundamental para que as pesquisas aplicadas possam vir a ser implementadas (Hamon et al., 1990).

O manejo eficiente de germoplasma vegetal é de vital importância para o pesquisador, pois este precisa de uma certa quantidade de germoplasma geneticamente puro e bem caracterizado, para utilizá-lo em suas pesquisas e para o melhoramento genético. Sendo assim, os marcadores baseados no polimorfismo de DNA, como RAPD (polimorfismo de DNA amplificado ao acaso), têm uma aplicação muito importante na administração de recursos genéticos, pois proporcionam dados básicos que são necessários ao melhoramento de plantas ou para o mapeamento de genes (Bretting \& Widrlechner, 1995). Os marcadores moleculares geram uma grande quantidade de caracteres adicionais que, combinados com características fenotípicas, fornecem um quadro mais completo para o agrupamento dos genótipos e o planejamento de cruzamentos, como, por exemplo, a identificação e discriminação de genótipos, a quantificação da variabilidade genética existente ao nível de sequência de DNA (Ferreira \& Grattapaglia, 1995).
Nos últimos anos, a disponibilidade de marcadores RAPD permitiu estudos de diversidade genética e/ou classificação de cultivares de diversas espécies como Arabidopsis, Eucalyptus, Heliantus anomalus, Vicia faba, Medicago sativa, soja, feijão, dentre outras (Penner, 1996). Porém, até o momento, as técnicas moleculares não foram empregadas na análise da diversidade em quiabeiro. Este trabalho tem por objetivo a utilização de marcadores RAPD para estimar a diversidade entre acessos do gênero Abelmoschus.

\section{MATERIAL E MÉTODOS}

Para o estudo da diversidade genética com base em marcadores RAPD, utilizaram-se 43 acessos, sendo 42 do gênero Abelmoschus e um do gênero Hibiscus. Dos 42 acessos de 
Abelmoschus spp, quinze são $A$. esculentus, quinze A. caillei, dois $A$. manihot, oito A. moschatus, um $A$. ficulneus e um A. tetraphyllus. Estes genótipos foram fornecidos pela Estação Regional da Geórgia de Introdução de Plantas do Departamento de Agricultura dos Estados Unidos (USDA), os quais foram solicitados através do Centro Nacional de Recursos Genéticos (CENARGEN/EMBRAPA) e atualmente estão sendo mantidos pelo Banco de Germoplasma da UENF. Os genótipos constam de espécies cultivadas e silvestres, de diversas procedências, conforme a Tabela 1.

As plantas foram cultivadas em vasos, em condição de casa de vegetação na Unidade de Apoio à Pesquisa da UENF. As amostras para análise dos marcadores de DNA foram constituídas de discos foliares obtidos de cinco plantas de cada acesso, que foram embaladas, identificadas e mergulhadas em nitrogênio líquido. A extração de moléculas a partir de folhas de quiabeiro foi realizada no Laboratório de Melhoramento Genético Vegetal do CCTA, com base no protocolo desenvolvido por Doyle \& Doyle (1990).

Para o isolamento do DNA, foram utilizados cerca de $500 \mathrm{mg}$ da mistura de tecidos macerados obtidos a partir de discos foliares das cinco plantas. Ao tecido foi adicionado $700 \mathrm{ml}$ de CTAB com forte agitação em vortex por 30 segundos. A mistura foi incubada a $60^{\circ} \mathrm{C}$ por 1 hora e centrifugada para a retirada de impurezas brutas. O sobrenadante passou por duas extrações com clorofórmio-álcool isoamílico (24:1), ambas seguidas por centrifugação (14.000 rpm, por 5 minutos em centrífuga Eppendorf modelo 5415 C). Para a precipitação do DNA, foi adicionado $2 / 3$ do volume da amostra de isopropanol seguido por uma lavagem em etanol a $80 \%$. Após a secagem do pellet, o DNA foi ressuspenso em tampão TE $(0,01 \mathrm{M}$ Tris- $\mathrm{HCl}$; 0,001M EDTA) pH 8,00. Em seguida foi adicionado RNAse $\left(10 \mathrm{mg} \mathrm{ml}^{-1}\right)$ mantendo-se incubado por $30 \mathrm{~min}$ a $37^{\circ} \mathrm{C}$. Passou por uma nova lavagem com etanol (80\%) e, após, nova ressuspensão em TE. A concentração do DNA foi quantificada pelo fluorômetro Hoefer modelo DyNA Quant 200.
Para verificar a integridade do DNA, géis de agarose a 1,4\% foram preparados para eletroforese e, a cada poço do gel foi aplicada uma amostra de $3 \mathrm{ml} \mathrm{de}$ DNA. Após corrida a $100 \mathrm{~V}$ por 2 horas, os géis foram, então, banhados em brometo de etídio ( $0,5 \mathrm{mg} / \mathrm{litro})$ por 30 a 45 min à temperatura ambiente. A descoloração foi realizada imergindo o gel em água durante 20 min também a temperatura ambiente e o DNA visualizado pelo fotodocumentador Stratagene modelo Eagle Eye II.

Um acesso de cada espécie foi testado para 60 iniciadores para avaliar o polimorfismo de DNA, com o propósito de selecionar aqueles que amplificassem simultaneamente para todas as espécies. O procedimento de amplificação foi similar ao descrito por Williams et al. (1990). O procedimento de PCR («Polymerase Chain Reaction») foi realizado com $30 \mathrm{ng}$ de DNA, $0,1 \mathrm{mM}$ de cada dNTP (Perkin-Elmer, USA), 2,4 $\mathrm{mM}$ de $\mathrm{MgCl}_{2}$ (Perkin-Elmer, USA), $1 \mathrm{U}$ (unidade) de Taq DNA-Polimerase em tampão de PCR (Pharmacia Biotech, USA), $10 \mathrm{mM} / 50 \mathrm{mM}$ de Tris- $\mathrm{KCl}$ e 0,4 $\mathrm{mM}$ de iniciador (decâmero - Operon Technologies). As concentrações de cada componente foram ajustadas para o volume final de $25 \mathrm{ml}$ de reação com $\mathrm{H}_{2} \mathrm{O}$ ultra pura estéril. As condições da reação foram as seguintes: $1 \mathrm{~min}$ a $90^{\circ} \mathrm{C}$, seguida por 55 ciclos, cada ciclo constituindo as etapas de desnaturação (1 min, $94^{\circ} \mathrm{C}$ ), anelamento do iniciador (1 $\min , 36^{\circ} \mathrm{C}$ ) e extensão do iniciador (2 $\min , 72^{\circ} \mathrm{C}$ ). Após os 55 ciclos, foi inserido um ciclo de 7 min a $72^{\circ} \mathrm{C}$ para extensão final. As amplificações foram desenvolvidas em termociclador GeneAmp 9600 (Perkin-Elmer, USA).

Após a amplificação, o volume final da reação foi de $25 \mathrm{ml}$. Entretanto, adicionou-se $5 \mathrm{ml}$ de corante «Blue Juice» (6X) e o volume final passou para $30 \mathrm{ml}$. O DNA amplificado foi aplicado em gel de agarose a $1,4 \%$ em cuba de eletroforese horizontal e submetido a $100 \mathrm{~V}$ por 2 horas. Após a eletroforese, o gel foi banhado em brometo de etídio (0,5 ml/litro) por 30 a $45 \mathrm{~min}$ a temperatura ambiente. A descoloração foi realizada imergindo o gel em água durante 20 min também a temperatura ambiente e o DNA visualizado sob luz ultravioleta, para, a seguir, ser fotodocumentado e selecionados os iniciadores polimórficos a serem utilizados nos ensaios de RAPD.

Após a seleção dos iniciadores, procedeu-se o ensaio de polimorfismo de DNA amplificado ao acaso (RAPD), utilizando-se a técnica de PCR descrita anteriormente (Williams et al., 1990). A leitura das bandas no gel foi feita pela tabulação dos resultados em 0 ou 1, respectivamente para ausência ou presença de banda e 2 para os dados perdidos ou dúbios. A tabela de dados binários resultante foi utilizada para análise da divergência genética dos 43 acessos de quiabeiro.

Na interpretação dos resultados, gerou-se uma matriz de dissimilaridade genética a partir do complemento aritmético do Índice de Jaccard (Sneath \& Sokal, 1973), representado por:

$$
\mathrm{C}_{\mathrm{ij}}=1-\frac{\mathrm{a}}{\mathrm{a}+\mathrm{b}+\mathrm{c}}, \text { em que: }
$$

$\mathrm{a}=$ número de casos em que a banda está presente nos dois genótipos, simultaneamente; $b=$ número de casos em que a banda está presente somente no genótipo i; c = número de casos em que a banda está presente somente no genótipo j.

Posteriormente, adotou-se o método hierárquico do «vizinho mais próximo» para o agrupamento dos acessos. No procedimento analítico, partindo-se da matriz de distâncias genéticas, procedeu-se a sucessivas identificações dos genótipos mais próximos, a partir do par mais semelhante, até que se estabeleceu um diagrama de árvore.

A distância entre um acesso $\mathbf{k}$ e um grupo formado pelos acessos $\mathbf{i}$ e $\mathbf{j}$, é dada por: $\mathrm{D}_{(\mathrm{ij}) \mathrm{k}}^{2}=\min \left(\mathrm{D}_{\mathrm{ik}}^{2} ; \mathrm{D}^{2}{ }_{\mathrm{jk}}\right)$,

em que:

$\mathrm{D}_{(\mathrm{ij)}) \mathrm{k}}^{2}$ é a distância entre o grupo ij e o acesso k, e min $\left(\mathrm{D}^{2}{ }_{\mathrm{ik}} ; \mathrm{D}^{2}{ }_{\mathrm{jk}}\right)$ é a menor distância entre os grupos de acessos ik e jk.

$\mathrm{O}$ agrupamento dos acessos foi feito, também, pela utilização do método de Tocher (Rao, 1952), da forma seguinte: a partir da matriz de distâncias genéticas identificou-se o par mais próximo que constituiu o primeiro grupo; concomitantemente, obteve-se q, que é 
o maior valor do conjunto de menores distâncias entre os acessos. A partir de então, avaliou-se a possibilidade de inclusão de outros acessos neste grupo, respeitando-se o critério da distância média intragrupo inferior a quaisquer distâncias intergrupos. Para tanto, procedeu-se à comparação entre o acréscimo no valor médio da distância dentro do grupo e o máximo permitido, comumente denominado q. A inclusão de um acesso em um grupo foi possível quando:

$$
\frac{\mathrm{D}^{2}{ }_{(\mathrm{ij}) \mathrm{k}}}{\mathrm{n}}<\theta \text {, em que: }
$$

$$
\mathrm{D}_{(\mathrm{ij}) \mathrm{k}}^{2}=\mathrm{D}_{\mathrm{ik}}^{2}+\mathrm{D}^{2}{ }_{\mathrm{jk}} \text {, em que: }
$$

$\mathrm{D}^{2}{ }_{\mathrm{ik}}=$ distância entre os acessos i e $\mathbf{k} ; \mathrm{D}^{2}{ }_{\mathrm{jk}}=$ distância entre os acessos $\mathbf{j} \mathrm{e}$ $\mathbf{k}$; e $\mathrm{n}=$ número de acessos que constitui o grupo original.

A partir da análise de agrupamento pelo método de Tocher, os genótipos pertencentes ao primeiro grupo foram reagrupados pelo método hierárquico do vizinho mais próximo, com o propósito de se verificar o novo perfil da divergência genética.

As análises genético-estatísticas foram realizadas com o auxílio do Programa Genes (Cruz, 1997).

\section{RESULTADOS E DISCUSSÃO}

Foram utilizados 31 iniciadores, previamente selecionados por exibirem pelo menos uma banda polimórfica no gel para os 43 genótipos de quiabeiro. Nenhum destes oligonucleotídios mostrou monomorfismo, provavelmente por estarem envolvidas diversas espécies do gênero Abelmoschus e também um acesso do gênero Hibiscus. Os 31 iniciadores amplificaram um total de 103 fragmentos polimórficos, na proporção de 3,3 RAPDs por iniciador. Até 6 fragmentos foram polimórficos para diversos iniciadores.

Os acessos de número 1293, 1294, 1295, 1300, 1305, 1322, 1323 e 1324, identificados na Tabela 1 como $A$. manihot, mostraram-se tanto fenotipica como genotipicamente muito similares a A. caillei, portanto serão considerados como pertencentes à última espécie, o

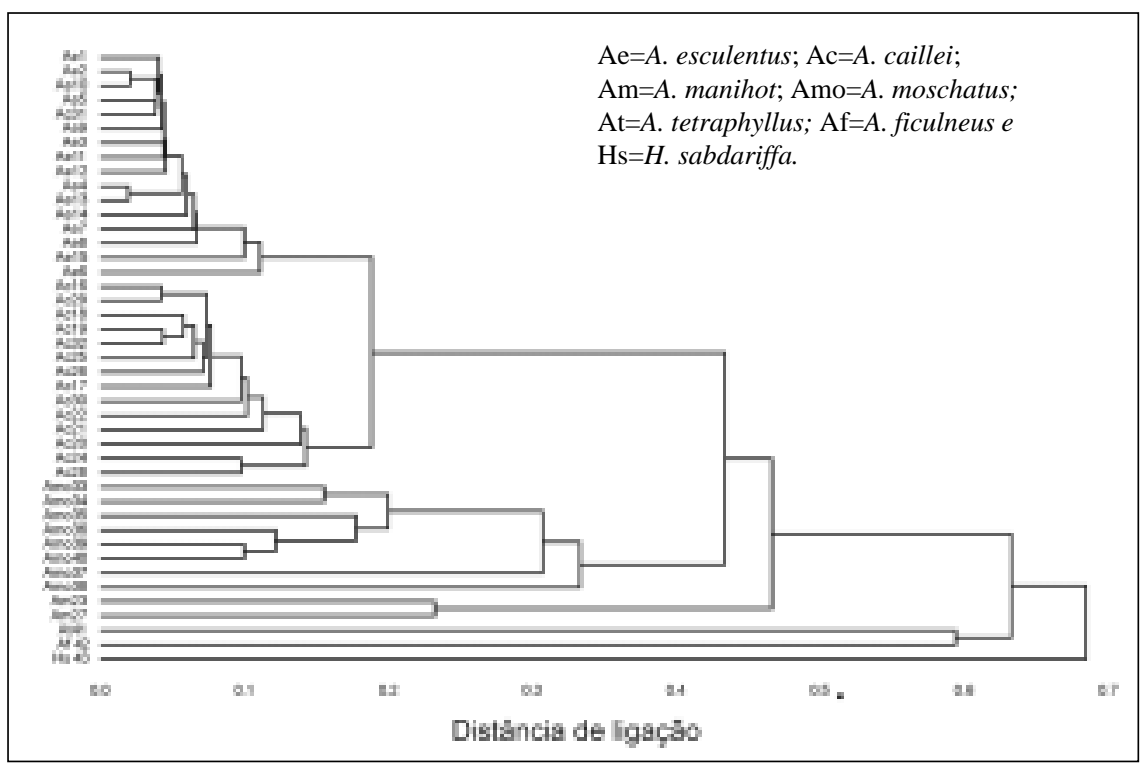

Figura 1. Dendrograma da dissimilaridade genética de 43 genótipos de quiabeiro, estabelecido pelo método hierárquico do vizinho mais próximo utilizando-se o complemento aritmético do índice de Jaccard, com base em marcadores RAPD. Campos (RJ), UENF, 1999.

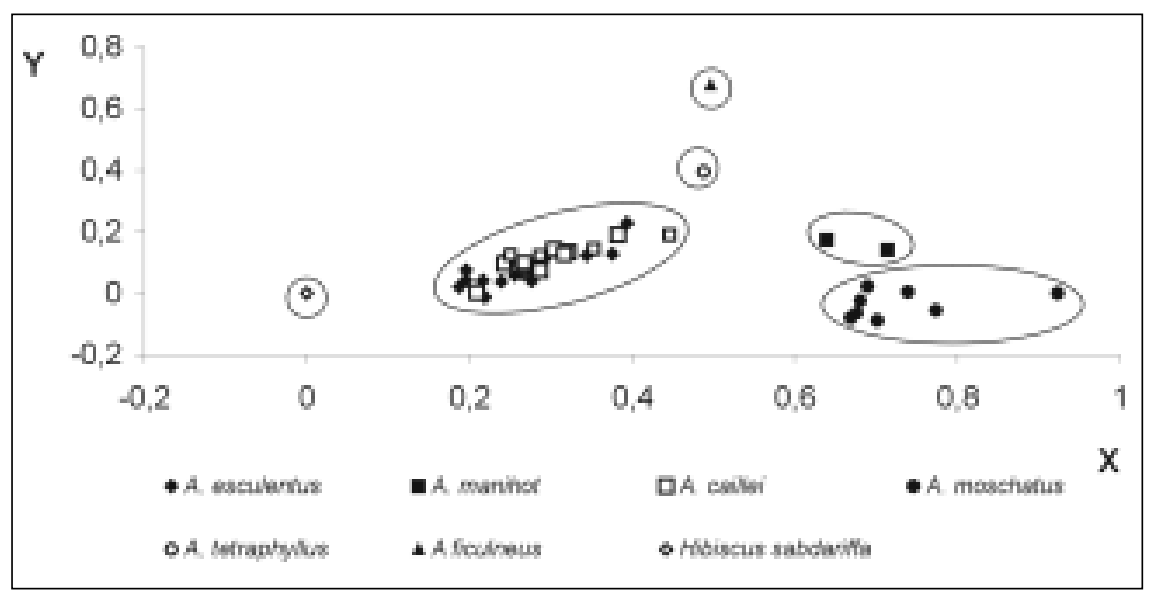

Figura 2. Projeção de distâncias genéticas, para sistemas cartesianos, de 42 acessos de Abelmoschus spp. e 1 acesso de Hibiscus sabdariffa, obtidos a partir de marcadores RAPD. Campos (RJ), UENF, 1999.

que é fundamentado pelo fato de que estes acessos são provenientes do oeste africano, onde são, muitas vezes, tratados como A. manihot, embora a descrição correta seja $A$. caillei. Existe, ainda, a possibilidade de ocorrência de erro na descrição dos acessos no Banco de Germoplasma, pois A. caillei é considerada uma espécie distinta e não mais uma variedade de A. manihot.

O agrupamento dos 43 genótipos com base no método hierárquico do vizinho mais próximo, utilizando marcadores RAPD, separou os acessos, de modo geral, conforme as espécies botânicas, formando seis grupos distintos (Figura 1). O primeiro grupo foi composto pelos acessos de A. esculentus e A. caillei, por se mostrarem muito semelhantes. Os acessos com maior proximidade genética foram 4 e o 13 (A. esculentus var. Itaocara I e A. esculentus de Camarões), seguidos por 2 e 10 (A. esculentus, cv. Santa Cruz e A. esculentus da Algéria). Por outro lado, os acessos de $A$. esculentus que mostraram-se mais distantes foram os de número 6 e 15 ( $A$. esculentus da Síria e A. esculentus cv. Parbhani Kranti). Com relação aos acessos de A. caillei, os genótipos 16 com 29 e 19 com 32 formaram, respectivamente, os dois pares mais semelhantes.

O segundo grupo é composto pelos acessos de A. moschatus, o terceiro pe- 
Tabela 1. Lista dos acessos de Abelmoschus spp. e suas procedências. Campos (RJ), UENF, 1999.

\begin{tabular}{|c|c|c|c|}
\hline $\begin{array}{c}\text { Material } \\
\mathbf{N}^{\circ}\end{array}$ & $N^{\circ}$ do acesso & Identificação da espécie & Procedência \\
\hline 01 & 1367 & A. esculentus cv. Piranema & Itaguaí-RJ. \\
\hline 02 & 1368 & A. esculentus cv. Santa Cruz 47 & Itaguaí-RJ. \\
\hline 03 & 1369 & A. esculentus cv. Pusa Sawani & Índia \\
\hline 04 & 1370 & A. esculentus var. Itaocara I & Itaocara-RJ. \\
\hline 05 & 1371 & A. esculentus var. Itaocara II & Itaocara-RJ \\
\hline 06 & 1291 & A. esculentus & Síria \\
\hline 07 & 1304 & A. esculentus & Paquistão \\
\hline 08 & 1307 & A. esculentus & Nigéria \\
\hline 09 & 1310 & A. esculentus & Burkina Faso \\
\hline 10 & 1311 & A. esculentus & Algéria \\
\hline 11 & 1312 & A. esculentus & Síria \\
\hline 12 & 1313 & A. esculentus & Zambia \\
\hline 13 & 1314 & A. esculentus & Camarões \\
\hline 14 & 1315 & A. esculentus & Sudão \\
\hline 15 & 1321 & A. esculentus cv. Parbhani Kranti & Índia \\
\hline 16 & 1372 & A. caillei & Índia \\
\hline 17 & 1284 & A. caillei & Costa do Marfim \\
\hline 18 & 1288 & A. caillei & Costa do Marfim \\
\hline 19 & 1290 & A. caillei & Costa do Marfim \\
\hline 20 & 1301 & A. caillei & Costa do Marfim \\
\hline 21 & 1306 & A. caillei & Costa do Marfim \\
\hline 22 & 1309 & A. caillei & Costa do Marfim \\
\hline 23 & 1373 & A. manihot & Índia \\
\hline 24 & 1293 & A. manihot & Togo \\
\hline 25 & 1294 & A. manihot & Guiné \\
\hline 26 & 1295 & A. manihot & Togo \\
\hline 27 & 1297 & A. manihot & Japão \\
\hline 28 & 1300 & A. manihot & Burkina Faso \\
\hline 29 & 1305 & A. manihot & Camarões \\
\hline 30 & 1322 & A. manihot & Costa do Marfim \\
\hline 31 & 1323 & A. manihot & Benin \\
\hline 32 & 1324 & A. manihot & Guiné \\
\hline 33 & 1289 & A. moschatus & Benin \\
\hline 34 & 1296 & A. moschatus & Benin \\
\hline 35 & 1302 & A. moschatus & Benin \\
\hline 36 & 1303 & A. moschatus & Togo \\
\hline 37 & 1316 & A. moschatus & Benin \\
\hline 38 & 1317 & A. moschatus & Costa do Marfim \\
\hline 39 & 1318 & A. moschatus & Benin \\
\hline 40 & 1320 & A. moschatus & Benin \\
\hline 41 & 1374 & A. tetraphyllus & Índia \\
\hline 42 & 1375 & A. ficulneus & Índia \\
\hline 43 & 1376 & Hibiscus sabdariffa & Bom Jardim-RJ \\
\hline
\end{tabular}


Tabela 2. Agrupamento pelo método de otimização de Tocher, de 43 genótipos de quiabeiro, com base em marcadores RAPD, utilizando o complemento aritmético do Índice de Jaccard. Campos (RJ), UENF, 1999.

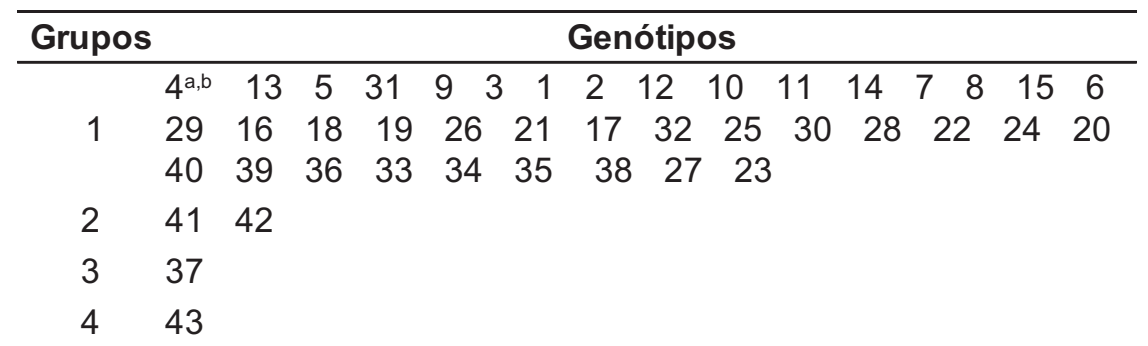

a seqüência dos números indica a entrada dos genótipos no grupo.

${ }_{b}$ A identificação dos genótipos encontram-se na Tabela 1 .

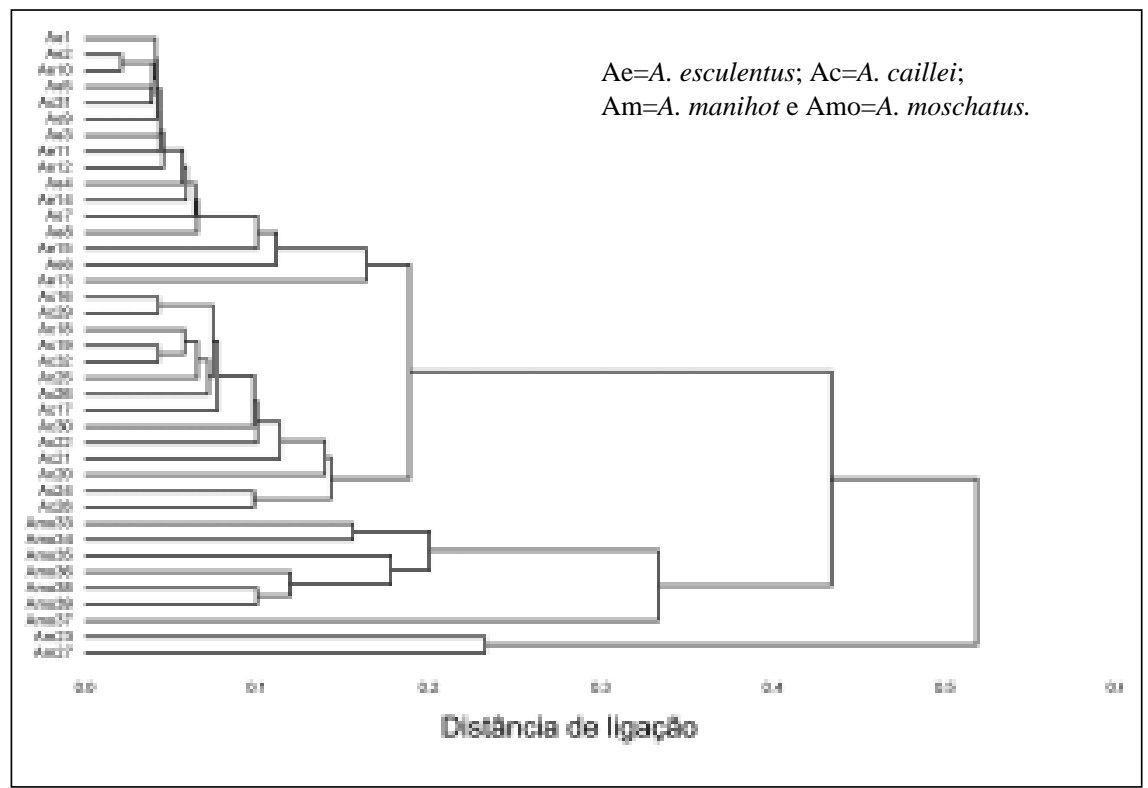

Figura 3. Redistribuição hierárquica dos genótipos do grupo I de Tocher, com base em marcadores RAPD, analisados pelo método do vizinho mais próximo. UENF - Campos (RJ), 1999.

los acessos de $A$. manihot, o quarto envolveu a espécie $A$. tetraphyllus e o quinto, A. ficulneus. A espécie $H$. sabdariffa formou, separadamenrte o grupo 6 , mostrando ser a mais distante dentre os 43 acessos avaliados.

A projeção das distâncias genéticas no plano bidimensional (Figura 2), foi eficaz na separação dos acessos. Por esta figura, pode-se observar que os acessos de A. esculentus e de A. caillei, formaram um único grupo. Este resultado está de acordo com o agrupamento pelo método hierárquico (Figura 1), quando procede-se um corte vertical a uma distância de ligação de aproximadamente 0,35. Assim, as espécies $A$. esculentus e $A$. caillei revelaram semelhanças genéticas em elevada magnitude, constituindo genomas muito aproximados.
Martinello et al. (1996), numa análise por componentes principais aplicada a características morfológicas em quiabeiro, verificaram que a espécie $A$. caillei foi a única das silvestres que fez parte do grupo em que todos os outros acessos eram A. esculentus. Estes autores verificaram, ainda, que hibridações interespecíficas entre $A$. caillei $(2 \mathrm{n}=$ 185-189) e A. esculentus $(2 \mathrm{n}=72-144)$ foram eficazes e que, os híbridos $F_{1}$ são férteis e produzem grandes quantidades de sementes viáveis, apesar da diferença do número de cromossomos entre os parentais. Isto indica uma grande afinidade entre os genomas, que podem fazer parte de um mesmo «pool» gênico. Estas constatações denotam que, no processo de evolução, estas espécies diver- giram ou bifurcaram mais recentemente. Talvez A. caillei se diferenciou de $A$. esculentus, ou vice-versa, por um processo evolucionário reticulado, isto é, anfiploidização, poliploidização, hibridação ou outro sistema genético (Baum \& Gupta, 1996). Convém salientar que este tipo de situação envolvendo evolução reticulada para as plantas superiores, ainda é muito pouco estudado. Siemonsma (1982) hipotizou que $A$. caillei é um anfiplóide natural de $A$. esculentus $(2 \mathrm{n}=130-140)$ e A. manihot $(2 n=60-68)$.

Ainda com relação à análise gráfica das distâncias genéticas no plano bidimensional (Figura 2), as espécies representadas por apenas um acesso formaram grupos individuais, como é o caso de A. tetraphyllus, A. ficulneus e Hibiscus sabdariffa. Os acessos de $A$. moschatus e A. manihot também formaram grupos separados. Sendo assim, os marcadores RAPD foram capazes de classificar e também diferenciar corretamente as espécies, com exceção do genótipo 31 (A. caillei) que se assemelhou aos acessos de $A$. esculentus.

A aplicação do método de agrupamento por otimização de Tocher, utilizando a matriz de distâncias obtidas pelo complemento aritmético do Índice de Jaccard, permitiu a formação de quatro grupos distintos (Tabela 2). O grupo 1 é composto pelos acessos de A. caillei, $A$. esculentus, A. moschatus e A. manihot, sendo que os acessos das espécies $A$. caillei e A. esculentus mostraram-se altamente similares e estão representados pelos genótipos de número $4,13,5,31$, $9,3,1,2,12,10,11,14,7,8,15,6,29$, $16,18,19,26,21,17,32,25,30,28$, 22, 24 e 20. Neste grupo, os acessos de número 4 e 13 são os mais próximos. Os genótipos de números 40, 39, 36, 33, 34,35 e 38 pertencem a espécie $A$. moschatus e os de número 27 e 23 , à espécie A. manihot que, por sua vez, mostraram-se mais distantes em relação às espécies A. caillei e A. esculentus. $\mathrm{O}$ grupo 1 compreendeu aproximadamente $90 \%$ do germoplasma avaliado, indicando baixa amplitude da variabilidade genética nos genótipos em estudo.

A análise de agrupamento por otimização de Tocher, mostrou-se coerente apenas em parte à análise de 
agrupamento hierárquico, vez que o grupo 1 conteve, além das espécies $A$. esculentus e A. caillei, A. moschatus e A. manihot. $O$ grupo 2 compreendeu $A$. tetraphyllus e A. ficulneus. Por sua vez, A. moschatus compôs o grupo 3 e $H$. sabdariffa o grupo 4.

Quando aplicou-se o método hierárquico do vizinho mais próximo apenas sobre o grupo I de Tocher (Tabela 2), houve, consequentemente, o surgimento de seis fragmentos monomórficos, resultando 88 locos polimórficos. Esse polimorfismo foi reanalisado pelo complemento aritmético do Índice de Jaccard. A redistribuição hierárquica dos 39 genótipos que compunham o grupo I de Tocher (Figura 3), mostrou-se bastante semelhante ao apresentado pela Figura 1, sendo que na Figura 3 houve a formação de quatro grupos, quando passa-se uma linha vertical a uma distância de 0,35 . O primeiro grupo reuniu mais uma vez os acessos de $A$. esculentus e A. caillei. Os acessos 2 e 10 mostraramse, desta vez, os mais próximos, porém o acesso 13 mostrou-se mais distante com relação aos demais do mesmo grupo, inclusive afastando-se bastante do acesso 4, que na Figura 1 apresentou-se intimamente associado àquele. $\mathrm{O}$ grupo 2 , da Figura 3, permaneceu idêntico ao grupo 2 da Figura 1. O grupo 3 reuniu os acessos de A. manihot que, por sua vez, mostraram-se os mais distantes dentre os 39 avaliados. Assim, o reagrupamento dos acessos revelou a existência de uma heterogeneidade genética no grupo I que, desta forma, tornou os resultados da metodologia de Tocher semelhantes aos obtidos com o método hierárquico do vizinho mais próximo.

O reagrupamento tem sido utilizado por alguns autores, como forma alternativa de tornar os resultados mais elucidativos. Amaral Júnior (1996), por exemplo, trabalhando com tomateiro, subdividiu o grupo I de Tocher, em dois subgrupos para uma melhor comparação entre a diversidade obtida com marcadores RAPD e características morfoagronômicas. Vasconcellos (1995), por sua vez, trabalhando com feijoeiro, também procedeu à redistribuição intragrupo para uma melhor visualização das distâncias entre os indivíduos que foram separados com base nos padrões de faseolina e nos tamanhos de sementes.

Com esta pesquisa verificou-se que os marcadores RAPD foram eficientes no estudo da diversidade genética do quiabeiro. Verificou-se ainda que as técnicas estatísticas empregadas foram capazes de estabecer padrões e classificações da diversidade genética, revelando a formação de seis grupos. O agrupamento pelo método hierárquico do vizinho mais próximo, com base nos marcadores RAPD, revelou que os acessos de A. esculentus, apesar das diferentes procedências, são bastante homogêneos e que estão muito próximos de $A$. caillei. O reagrupamento dos acessos, por sua vez, revelou a existência de uma heterogeneidade genética no grupo I que, desta forma, tornou os resultados da metodologia de Tocher semelhantes aos obtidos com o método hierárquico do vizinho mais próximo. Este trabalho apresentou informações valiosas que podem ser utilizadas na escolha de progenitores mais adequados para iniciar um programa de melhoramento da cultura em questão.

\section{AGRADECIMENTOS}

Agradeço à Fundação Estadual Norte Fluminense (FENORTE) pela concessão da bolsa de estudos.

\section{LITERATURA CITADA}

AMARAL Jr, A.T. Análise dialélica de betacaroteno, vitamina $C$, sólidos solúveis e produção e variabilidade em cultivares de tomateiro (Lycopersicon esculentum Mill.) via marcadores $R A P D$. Viçosa: UFV. Imprensa Universitária, 1996, 198 p. (Tese doutorado).
BAUM, B.R.; GUPTA, P.K. Numerical taxonomy and genome analysis. In: JAUHAR, P.P. (ed.) Methods of genome analysis in plants. North Dakota: CRC Press, 1996. p. 345-356.

BRETTING, P.K.; WIDRLECHENER, M.P. Genetic markers and horticultural germplasm management. HortScience, v. 30, n. 7, p. 13491355, 1995.

CRUZ, C.D. Programa Genes: aplicativo computacional em genética e estatística. Viçosa, MG: Editora UFV, 1997. 442 p.

DOYLE, J.J.; DOYLE, J.L. Isolation of plant DNA from fresh tissue. Focus, v. 12, p. 13-15, 1987.

FERREIRA. M.E.; GRATTAPAGLIA, D. Introdução ao uso de marcadores RAPD e RFLP em análise genética. Brasília: MAARA/EMBRAPA/ CENARGEN, 1995. 220 p.

HAMON, S.; CHARRIER, A.; KOEKLIN, J.; VAN SLOTEN, D.H. Potential contributions to okra breeding through the study of their genetic resources. In: REPORT OF AN INTERNATIONAL WORKSHOP ON OKRA GENETIC RESOURCES. 1990, New Delhi. Anais... Roma: IBPGR, 1991. p. 77-88.

MARTINELLO, G.E.; ABBOUD, A.C.S.; LEAL, N.R. Análise em componentes principais e de agrupamentos aplicada a características morfológicas e agronômicas em quiabeiro. Horticultura Brasileira, v. 14, n. 2, p. 200-203, 1996.

PENNER, G.A. RAPD analysis of plant genomes. In: JAHUAR, P.P. (ed.) Methods of genome analysis in plants. Dakota: CRC Press, 1996. p. 251-264.

RAO, C.R. Advanced statistical methods in biometric research. New York: John-Wiley and Sons, 1952. 389 p.

SIEMONSMA, J.S. West-African okra morphological and cytogenetical indications for the existence of a natural amphidiploid of Abelmoschus esculentus (L.) Moench and A. manihot (L.) Medikus. Euphytica, v. 31, n. 1, p. 241-252, 1982.

SNEATH, P.H.; SOKAL, R.R. Numerical taxonomy: The principles and pratice of numerical taxonomy. San Francisco: W.H. Freeman, 1973. $573 \mathrm{p}$.

VASCONCELOS, M.J.V. Avaliação da variabilidade genética de cultivares de feijão (Phaseolus vulgaris $\mathrm{L}$.) pelo uso de marcadores moleculares $R A P D$. Viçosa: UFV. Imprensa Universitária, 1995, 54 p. (Tese mestrado).

WILLIAMS, J.G.K.; KUBELIK, A.R.; LIVAK, K.J.; RAFALSKI, J.A.; TINGEY, S.V. DNA polymorphisms amplified by arbitrary primers are useful as genetic markers. Nucleic acid Research, v. 18 , p. $6531-6535,1990$. 